\title{
Relationships among Indices for the End of Bud Dormancy in Apple Cultivars and Related Malus Species under Cold Winter Conditions
}

\author{
Roberto Hauagge ${ }^{1}$ and James N. Cummins \\ Department of Horticultural Sciences, New York State Agricultural Experiment Station, Cornell \\ University, Geneva, NY 14456
}

Additional index words. chilling, rest, budbreak

\begin{abstract}
Relationships among estimates for the length of bud dormancy over a wide range of cultivars of Malus $\times$ domestics Borkh. and related Malus spp. are reported. Flower bud dormancy state was estimated after fitting quadratic models for the number of days for $50 \%$ terminal budbreak (D50), bud development stage (BDS), and percent terminal budbreak (BB) after 21 days of forcing as a function of chilling unit (CU) accumulation. Cultivar, linear, and quadratic components of regression, as well as all interactions, were significant for D50, BDS, and BB when regressed against $\mathrm{CU}$ accumulation. Consequently, cultivars differ not only as to when changes in "dormancy intensity take place, but also in the patterns and rates at which these changes proceed. The number of CU needed to reach arbitrary stages of each characteristic at the end of dormancy was calculated and compared for all genotypes. Rates of CU accumulation until BB, BDS, and D50 reached 50\%, 1.5 and 15 days, respectively, were well-correlated. These CU values were considered the end of bud dormancy or genotype chilling requirement (CR). Estimations of D50 were less variable and less subjective, and a wider range of data points could be used in the analysis. In addition, values for D50 can indicate the growth potential of buds when other indices do not show changes. A few sampling times during the dormant season may give a preliminary idea about the CR of a given genotype.
\end{abstract}

Bud dormancy in woody species is generally induced naturally in late summer and fall and is broken by low temperatures that occur during fall, winter, and spring. Temperature is the main factor that affects dormancy release. The efficiency of temperature to release buds from dormancy depends on its absolute value and on the range of temperatures in daily or longer cycles (Bennett, 1949; Couvillon and Erez, 1985b; Erez et al., 1979a, 1979b; Overcash and Campbell, 1955; Samish and Lavee, 1962). The "chill-unit model" developed by Richardson et al. (1975) takes into consideration the effects of various temperatures on the dormancy-breaking process; it usually has been useful in temperate climate zones (Shaltout and Unrath, 1983).

Bud dormancy status is estimated by measurement of growth rate or developmental stage of terminal, lateral, or isolated buds in excised shoots or small plants after buds have been exposed to environmental conditions favorable for growth (Couvillon and Erez, 1985a; Hatch and Walker, 1969; Landsberg, 1974; Latimer and Robitaille, 1981; Paiva and Robitaille, 1978a, 1978b; Shaltout and Unrath, 1983; Singha and Powell, 1978; SpiegelRoy and Alston, 1979; Williams et al., 1979). To determine $50 \%$ flower bud growth, plants are subjected to temperatures of 16 to $24 \mathrm{C}$ and 16 to $24 \mathrm{~h}$ of light. In that protocol, dormancy is generally considered over when $50 \%$ budbreak occurs within 14 to 21 days. The purpose of this study was to compare the different estimation indices for the length of the bud dormancy period in a wide range of apple cultivars and related Malus spp. growing under cold winter conditions. The $\mathrm{CR}$ of apple cultivars (Hauagge and Cummins, 1991a) and the seasonal variation in bud dormancy intensity (Hauagge and Cummins, 1991b) are considered in companion papers.

Received for publication 1 Aug. 1989. We thank L.E. Powell and R.D. Way for critical review of this manuscript, and R.D. Way and R.C. Lamb for providing apple shoots from the collection at Geneva, N.Y. The cost of publishing this paper was defrayed in part by the payment of page charges. Under postal regulations, this paper therefore must be hereby marked advertisement solely to indicate this fact.

'Present address: IAPAR-Instituto Agronômico do Paraná, P.O. Box 2301, Curitiba, PR, Brazil 80001.

\section{Materials and Methods}

Field sampling. Dormant, previous season's apple shoots 15 to $25 \mathrm{~cm}$ long having terminal flower buds were collected from trees growing at the New York State Agricultural Experiment Station, Geneva, during 1984-85 (20 sampling times between 22 Oct. 1984 and 27 Mar. 1985), 1985-86 (16 sampling times between 24 Sept. 1985 and 28 Apr. 1986), and 1986-87 (12 sampling times between 14 July 1986 and 13 Apr. 1987) fall/ winter seasons. Leaves were removed when necessary, and shoots were forced in continuous light and at constant temperature (23 $\pm 1 \mathrm{C}$ in $1984-85$ and $1985-86$; $19 \pm 1 \mathrm{C}$ in 1986-87). During forcing, shoots were covered with perforated transparent plastic bags to avoid excessive desiccation. Shoots were inspected every 3rd day when the water in the containers was replaced, and their bases were recut every week. Continuous water flow was used in the 1986-87 sampling, which allowed for the maintenance of the shoots under forcing conditions for much longer periods. The number of $\mathrm{CU}$ accumulated at the sampling time was determined by: $\mathrm{CU}=0.2770+0.1940 \mathrm{t}-0.0124 \mathrm{t}^{2}(\mathrm{~A}$. Lakso, personal communication) fitted from Shaltout and Unrath's (1983) data, where $t$ is the hourly recorded temperature.

After 21 days of forcing, BDS (1984-85 and 1985-86) and BB (1985-86) were assessed. Seven bud development classes were assigned, based on Chapman and Catlin (1976), where: 0 $=$ dormant buds, $0.5=$ silvertip, $1=$ greentip, $2=1.2 \mathrm{~cm}$ (0.5 inch) green, $3=$ tight cluster, $4=$ pink, $5=$ bloom, and 6 = petal fall. D50, i.e., when buds reached stage 1, was monitored in 1985-86 (within the 21-day forcing period) and 1986-87 (35 to 180 days of forcing period, which was limited by the shoot maturation stage). Shoots with terminal buds removed were also used on five sampling dates in the 1986-87 experiments. Growing degree hours (GDH) (Anderson et al., 1986) was calculated assuming optimum (25C) and base (4C) temperatures for apple growth.

Abbreviations: BB, percent terminal budbreak; BDS, bud development stage; $\mathrm{CR}$, chilling requirement; $\mathrm{CU}$, chill unit; D50, number of days for $50 \%$ terminal budbreak; GDH, growing degree hours. 
Arrangement of shoots was completely randomized, with each observation unit consisting of two shoots replicated three times in 1984-85 and four shoots replicated four times in 1985-86 and 1986-87. The data were subjected to regression analysis for the best fitted function, linear or quadratic. Only the last data point, the value of which was zero, was used in the regression for the bud development data. Regression was fitted for $\mathrm{BB}$ after removing zero and 100 values.

\section{Results and Discussion}

Field CU and GDH accumulation patterns were similar during the three experimental years (Figs. 1 and 2). No significant $\mathrm{GDH}$ were accumulated in Geneva during winter.

Intact shoots. The patterns for D50 and both BDS and BB after 21 days of forcing as a function of $\mathrm{CU}$ accumulation for 'Anna' and 'Empire' are represented in Fig. 3. A quadratic model fit better than a linear one for the D50 and BDS in all experimental years and all cultivars. Many genotypes had shown some tendency to shift the D50 to the right. This shift can be observed when good linear fit was obtained by plotting the inverse of D50 (Fig. 3F). However, not all cultivars showed this tendency (Fig. 3B), and usually very little or no improvement

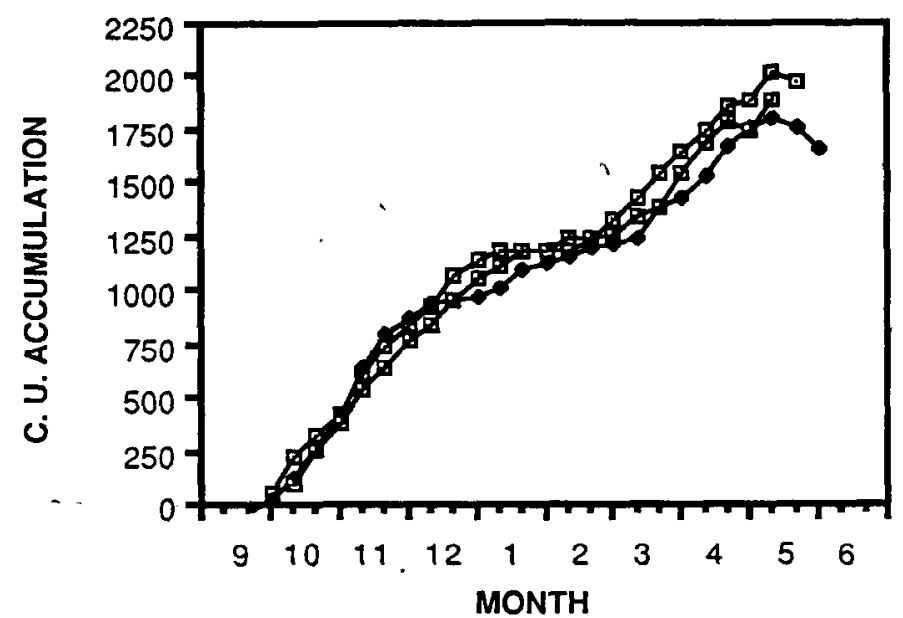

Fig. 1. CU accumulation in the 1984-85 ( $-\square-$ ), 1985-86 (- - ), and 1986-87 (-๑-) seasons at the New York State Agricultural Experiment Station, Geneva.

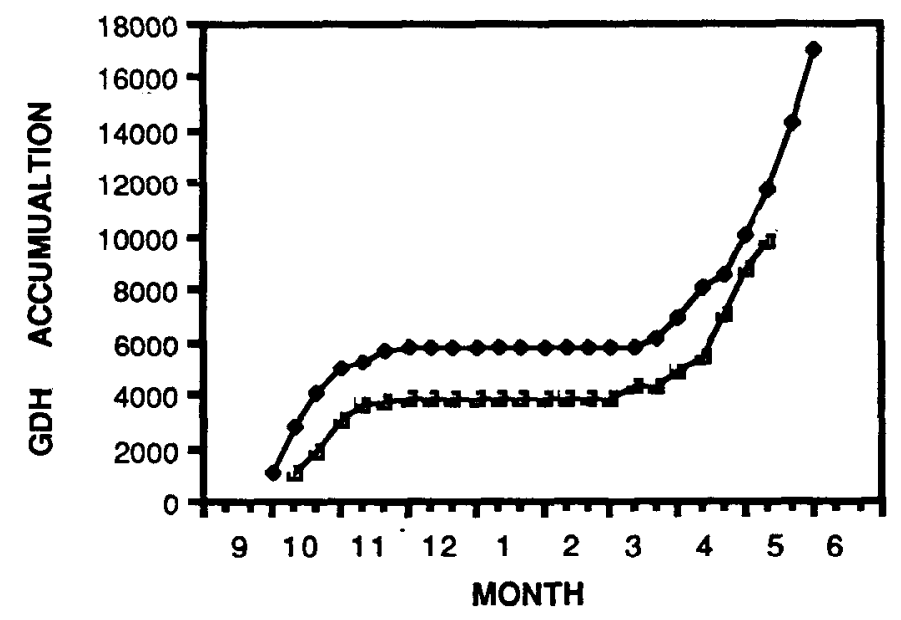

Fig. 2. GDH accumulation in the 1985-86

and $1986-87$ seasons at the New York State Agricultural Experiment Station, Geneva. Accumulation started at the $0 \mathrm{CU}$ day. for the fitting was observed with these data. In this way, cultivar $\mathrm{CU}$ requirement values determined on BDS and D50 bases were interpolated from a 2nd-degree function. Either BDS or BB values were maintained at or near the 0 level, and then they rose abruptly in most cultivars (Figs. $3 \mathrm{G}$ and $\mathrm{H}$ ); however, in some cultivars with low depth of bud dormancy (Fig. 3D), this rise did not occur. In this situation, buds always developed within the forcing period.

Cultivar, linear, and quadratic components of regression, as well as all interactions, were significant for D50, BDS, and BB when regressed against $\mathrm{CU}$ accumulation (Table 1). Identical trends were also observed in the 1984-85 and 1986-87 seasons (data not shown). This result indicates that apple genotypes differ not only as to when changes in dormancy intensity take place, but also in the patterns and rates at which these changes proceed. This exemplifies the complexity of dormancy phenomena when one tries to consider a species as a whole. These particular genotype interactions imply that dormancy modelling must not be generalized or precision will be lost. These genotypic differences have implications for the adaptation of a particular genotype to diverse environmental conditions (Hauagge and Cummins, 1991b).

The means of the adjusted coefficient of determination for the quadratic fitting of D50 as a function of CU accumulation for all cultivars and Malus spp. were $0.79 \pm 0.13$ (0.56 to 0.96 ) and $0.82 \pm 0.12$ (0.64 to 0.99$)$ for the 1985-86 and 1986-87 seasons, respectively. The values were similar to those obtained when the same data were fitted on the basis of the total GDH accumulation in the field and during forcing. Conse-

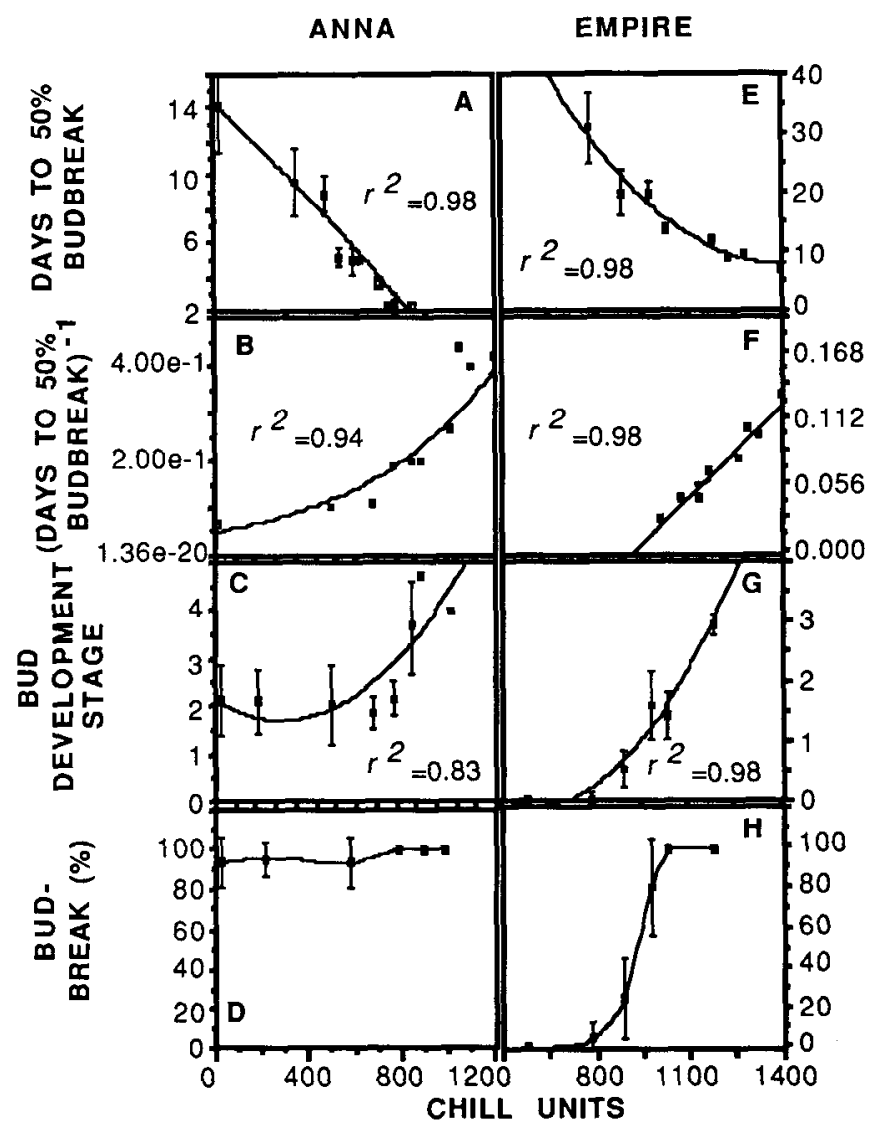

Fig. 3. Variation in the bud dormancy intensity in the apple cultivars Anna and Empire measured by D50, its reciprocal, BDS, and BB as related to the total $\mathrm{CU}$ accumulation in 1985-86. 
quently, except for very high CR genotypes, GDH accumulated in the field can be ignored if the termination of dormancy is the only point studied. The probability for the $\mathrm{F}$ value for the model was $\leq 0.001$ and, in most cases, $\leq 0.0001$.

The means of the adjusted coefficient of determination for the quadratic fitting of BDS (1984-85 and 1985-86) and BB (1985-86) as a function of CU accumulated for all cultivars. and Malus spp. were $0.80 \pm 0.13$ (0.53 to 0.98$), 0.67 \pm 0.13$ (0.41 to 0.94 ), and $0.66 \pm 0.19$ (0.42 to 0.93$)$, respectively. In all cases, the model was significant at $P \geq 0.05$.

The state of bud dormancy estimated by D50 is more precise than either BB or BDS because BB or BDS values varied abruptly from a minimum to a maximum within a short range of CU accumulation (Fig. 3). D50 values varied in a much wider range of CU accumulation; consequently, more data points could be used in the regression. In addition, D50 values showed less variability and were less subjective. D50 values are especially interesting because they indicate the growth potential of buds when other indices show no changes. This characteristic may permit better understanding of development of dormancy throughout the season. Similar data were reported for peaches, where GDH was a more sensitive parameter for the estimation of bud dormancy state than was BB (Scalabrelli and Couvillon, 1986).

We observed that well-matured, dormant apple shoots (close to the time of natural leaf fall and afterward) can withstand up to 170 days under forcing conditions if proper care is takenprevention of desiccation, weekly trimming of cutting bases, and constant running water. at 12 to $15 \mathrm{C}$. Grafted plants of some apple cultivars under an alternating-temperature regime had also shown budbreak after being maintained 170 days under mildtemperature forcing conditions (Hauagge and Cummins, 1991a).

Table 1. Analysis of variance components for the linear and quadratic effects of the CU accumulation in three methods for the evaluation of bud dormancy status in apple cultivars in the 1985-86 season.

\begin{tabular}{|c|c|c|c|}
\hline Source & $\mathrm{df}$ & $\begin{array}{l}\text { Mean } \\
\text { square }\end{array}$ & $\mathrm{F}$ value \\
\hline \multicolumn{4}{|c|}{ D50 } \\
\hline Cultivar & 97 & 135.1 & $22.67^{* *}$ \\
\hline \multicolumn{4}{|l|}{$\mathrm{CU}$} \\
\hline Linear & 1 & 38765.3 & $6502.96^{* *}$ \\
\hline Quadratic & 1 & 174.0 & $29.20^{* *}$ \\
\hline Linear $\times$ cultivar & 97 & 51.7 & $8.67^{* *}$ \\
\hline Quadratic $\times$ cultivar & 97 & 27.8 & $4.67^{* *}$ \\
\hline Experimental error & 1939 & 5.9 & \\
\hline \multicolumn{4}{|c|}{$B D S^{\mathrm{z}}$} \\
\hline Cultivar & 81 & 6.69 & $19.36^{* *}$ \\
\hline \multicolumn{4}{|l|}{ CU } \\
\hline Linear & 1 & 475.74 & $1377.21^{* *}$ \\
\hline Quadratic & 1 & 270.84 & $784.05^{* *}$ \\
\hline Linear $\times$ cultivar & 81 & 1.85 & $5.44 * *$ \\
\hline Quadratic $\times$ cullivar & 81 & 0.90 & $2.60 * *$ \\
\hline Experimental error & 1650 & 0.34 & \\
\hline \multicolumn{4}{|c|}{$B B^{\mathrm{z}}$} \\
\hline Cultivar & 76 & 9899.6 & $19.66^{* *}$ \\
\hline \multicolumn{4}{|l|}{$\mathrm{CU}$} \\
\hline Linear & 1 & 846596.8 & $1681.51 * *$ \\
\hline Quadratic & 1 & 2371.5 & $4.71^{*}$ \\
\hline Linear $\times$ cultivar & 76 & 2793.4 & $5.55^{* *}$ \\
\hline Quadratic $\times$ cultivar & 76 & 1742.1 & $3.46^{* *}$ \\
\hline Experimental error & 1346 & 503.5 & \\
\hline
\end{tabular}

Nonetheless, a larger sample would improve precision at the time of maximum dormancy stage because a higher variability is observed at this point.

The total accumulated CU value needed for each taxon to reach an average specific level of D50 (20,15, 10, or 5 days), BDS $(0.25,0.50,1.50$, and 2.00$)$, and BB $(25 \%, 50 \%, 75 \%$, or $100 \%$ ) was calculated by using fitted equations, and the values were correlated among themselves (Tables 2-4). D50 for

Table 2. Correlation coefficients between estimates for $\mathrm{CU}$ accumulation needed for D50 within 20,15, 10, and 5 days of forcing in several apple genotypes in the 1985-86 and 1986-87 seasons.

\begin{tabular}{lcccc}
\hline \hline \multirow{2}{*}{$1986-87$} & \multicolumn{4}{c}{$1985-86$ Estimates $^{\mathrm{z}}$} \\
\cline { 2 - 5 } Estimates & 20 days & 15 days & 10 days & 5 days \\
\hline 20 days & $0.72^{* * *}$ & $0.72^{* * *}$ & $0.64^{* * *}$ & $0.37^{* *}$ \\
& $\mathrm{n}=81$ & $\mathrm{n}=87$ & $\mathrm{n}=88$ & $\mathrm{n}=69$ \\
15 days & $0.70^{* * *}$ & $0.75^{* * *}$ & $0.72^{* * *}$ & $0.53^{* * *}$ \\
& $\mathrm{n}=81$ & $\mathrm{n}=87$ & $\mathrm{n}=88$ & $\mathrm{n}=69$ \\
10 days & $0.54^{* * *}$ & $0.58^{* * *}$ & $0.65^{* * *}$ & $0.54^{* * *}$ \\
& $\mathrm{n}=80$ & $\mathrm{n}=85$ & $\mathrm{n}=86$ & 0.67 \\
5 days & $0.20^{\text {NS }}$ & $0.27^{*}$ & $0.44^{* * *}$ & $0.52^{* * *}$ \\
& $\mathrm{n}=72$ & $\mathrm{n}=76$ & $\mathrm{n}=76$ & $\mathrm{n}=61$ \\
\hline
\end{tabular}

${ }^{2} \mathrm{n}=$ Number of genotypes used in the comparison.

$*, * *, * * *{ }^{\mathrm{Ns}}$ Significant at $\mathrm{P}=0.05,0.01$, or 0.001 or nonsignificant, respectively.

Table 3. Correlation coefficients between the number of accumulated $\mathrm{CU}$ required for terminal buds to reach $0.25,0.50,1.00,1.50$, and 2.00 BDS within 21 days of forcing in several apple genotypes in the 1984-85 and 1985-86, seasons.

\begin{tabular}{cccccc}
\hline \hline \multirow{2}{*}{ 1985-86 } & \multicolumn{5}{c}{ 1984-85 Estimates ${ }^{\mathrm{z}, \mathrm{y}}$} \\
\cline { 2 - 6 } Estimates & BDS 0.25 & BDS 0.50 & BDS 1.00 & BDS 1.50 & BDS 2.00 \\
\hline BDS 0.25 & 0.54 & 0.62 & 0.67 & 0.66 & 0.61 \\
& $\mathrm{n}=51$ & $\mathrm{n}=52$ & $\mathrm{n}=54$ & $\mathrm{n}=55$ & $\mathrm{n}=55$ \\
BDS 0.50 & 0.58 & 0.66 & 0.70 & 0.69 & 0.63 \\
& $\mathrm{n}=55$ & $\mathrm{n}=58$ & $\mathrm{n}=61$ & $\mathrm{n}=62$ & $\mathrm{n}=63$ \\
BDS 1.00 & 0.58 & 0.64 & 0.70 & 0.71 & 0.67 \\
& $\mathrm{n}=60$ & $\mathrm{n}=63$ & $\mathrm{n}=67$ & $\mathrm{n}=68$ & $\mathrm{n}=69$ \\
BDS 1.50 & 0.56 & 0.60 & 0.69 & 0.73 & 0.70 \\
& $\mathrm{n}=63$ & $\mathrm{n}=66$ & $\mathrm{n}=69$ & $\mathrm{n}=70$ & $\mathrm{n}=72$ \\
BDS 2.00 & 0.50 & 0.52 & 0.61 & 0.64 & 0.62 \\
& $\mathrm{n}=62$ & $\mathrm{n}=65$ & $\mathrm{n}=68$ & $\mathrm{n}=69$ & $\mathrm{n}=71$ \\
\hline
\end{tabular}

${ }^{2}$ All comparisons were significant at $P=0.001$.

${ }^{y} n=$ Number of genotypes used in the comparison.

Table 4. Correlations among the amount of accumulated CU needed for buds to reach specific levels of the parameters D50, BDS (after 21 days of forcing), and BB (after 21 days of forcing) used to estimate the state of bud dormancy of apple genotypes in the 198586 seasons.

\begin{tabular}{|c|c|c|c|c|c|c|c|c|}
\hline \multirow[b]{2}{*}{ Criterion } & \multicolumn{4}{|c|}{ D50 } & \multicolumn{4}{|c|}{ BDS } \\
\hline & 20 & 15 & 10 & 5 & 0.25 & 1.00 & 1.50 & 2.00 \\
\hline \multicolumn{9}{|l|}{$\mathrm{BDS}$} \\
\hline 0.25 & $0.79^{z}$ & 0.64 & 0.51 & 0.36 & & & & \\
\hline 1.00 & 0.82 & 0.80 & 0.67 & 0.38 & & & & \\
\hline 1.50 & 0.75 & 0.75 & 0.67 & 0.44 & & & & \\
\hline 2.00 & 0.61 & 0.72 & 0.68 & 0.47 & & & & \\
\hline \multicolumn{9}{|l|}{$\mathrm{BB}$} \\
\hline 25 & 0.89 & 0.86 & 0.71 & 0.40 & 0.88 & 0.87 & 0.78 & 0.64 \\
\hline 50 & 0.89 & 0.70 & 0.55 & 0.30 & 0.86 & 0.90 & 0.83 & 0.63 \\
\hline 75 & 0.87 & 0.84 & 0.71 & 0.42 & 0.83 & 0.94 & 0.88 & 0.78 \\
\hline 100 & 0.62 & 0.79 & 0.75 & 0.51 & 0.76 & 0.88 & 0.80 & 0.80 \\
\hline
\end{tabular}

${ }^{2}$ All correlations were significant at $P=0.001$. 
15 days and BDS for 1.50 gave the highest correlation for independently obtained D50 (Table 2) and BDS (Table 3) value estimates. The correlation among independent estimations of either BDS and D50 showed some tendency to decrease in both sides (Tables 2 and 3 ) around the maximum values. BDS = 1.5 and D50 $=15$ values also correlated well when comparisons were made within the same year (Table 4), as well as with $\mathrm{BB}=50 \%$. The BDS mean value for all clones was determined to be equal to $1.66 \pm 0.44$ when calculated for $\mathrm{CU}$ values obtained from D50 equations at the 15th day of forcing.

According to the concept of Shaltout and Unrath (1983), dormancy is broken when further budbreak is not induced by additional CU. This may be precise, but it is difficult to determine experimentally. For practical purposes, however, dormancy should be considered to have been broken when no more visible symptoms of "delayed foliation" can be observed. This stage seems to be when budbreak occurred within 21 and 23 days (20C GDH equivalent) from the initial forcing day in 'Rome Beauty' and 'Golden Delicious', respectively (modified from Tabuenca and Jiménez, 1984). The values of these characteristics are close to those generally adopted to describe the end of the bud dormancy period.

Summarizing, the indices $\mathrm{BB}=50 \%, \mathrm{BDS}=1.5$, and $\mathrm{D} 50$ $=15$ correlated well among themselves, and they are close to values reported in the literature for the end of apple bud dormancy period.

Shoots from which terminal buds were removed. Decapitated shoots have been used to estimate the length of the bud dormancy period in Pyrus spp. (Spiegel-Roy ald Alston, 1979) and Malus spp. (Petropoulou, 1985). The uppermost bud of decapitated shoots will always break within a relatively short period, independently of sampling date (Paiva and Robitaille, 1978a; Williams et al., 1979). The dormancy intensity pattern of the uppermost bud may have a trend similar to that of terminal buds in intact shoots, but much less accentuated (Hauagge and Cummins, $1991 \mathrm{~b}$ ). The direct use of these data to create an index for-dormancy development was difficult because the differences in dormancy intensity in many genotypes are not clear. Considerable difference can be observed between Petropoulou's 1985 estimation of dormancy termination using decapitated shoots and that estimated by us (Fig. 4).

$\mathrm{CU}$ accumulation until the time when the ratio between the D50 in decapitated shoots and the D50 in intact shoots (D50R)

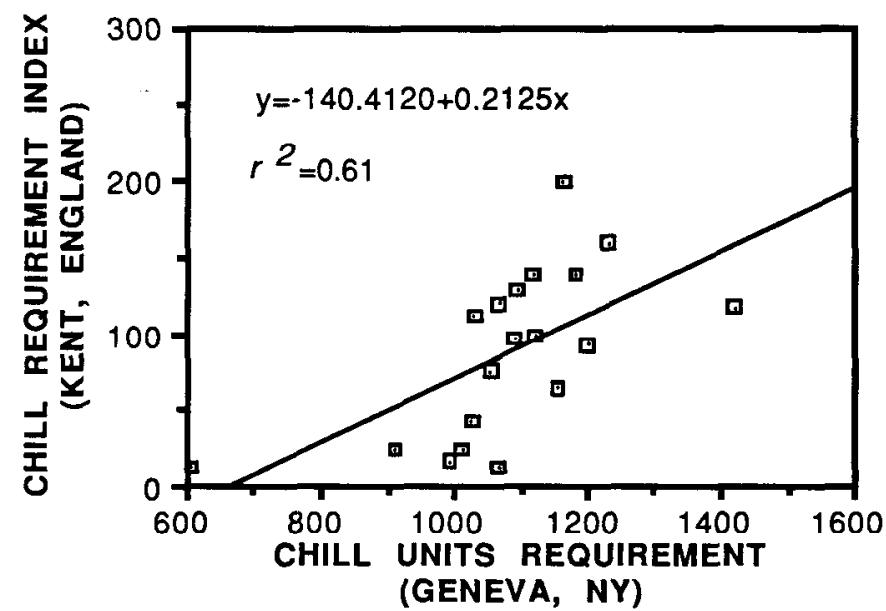

Fig. 4. Relationship between CR index using decapitated shoots estimated by Petropolou (1985) in Kent, England, and CU required to terminate terminal bud dormancy in Geneva, N.Y. is equal to one is relatively close to the other estimations of $\mathrm{CR}$ to terminate bud dormancy reported here $(\mathrm{BB}=50 \%$, BDS $=$ $1.5, \mathrm{D} 50=15$ ). These values were determined by fitting D50R obtained on five sampling dates into quadratic or linear equations (Hauagge, 1988). However, D50R indices of the end of dormancy (accumulated CU to D50R $=1$ ) are not as closely related to BB, BDS, and D50 indices as they are related to each other. For instance, correlations between D50R value estimates and BDS $=1.5(1984-85)$, D50 $=15(1985-86)$, and D50 = 15 (1986-87) were $0.46,0.48$, and 0.56 , respectively. All val-

Table 5. Correlation coefficients between bud CR to break dormancy in apple genotypes and the dormancy intensity of the same genotypes at different sampling dates during summer and winter. CR was considered to be equal to $\mathrm{CU}$ accumulated when D50 was equal to 15 days. Bud dormancy intensity was estimated by D50 in intact shoots, decapitated shoots, and by the ratio between decapitated and intact shoots at the time of sampling (1986-87 season).

\begin{tabular}{|c|c|c|c|c|c|}
\hline \multirow{2}{*}{$\begin{array}{l}\text { Sampling } \\
\text { date or } \\
\text { accumulated } \\
\text { CU }\end{array}$} & \multicolumn{5}{|c|}{ Cultivar CR vs. D50 } \\
\hline & \multicolumn{2}{|c|}{$\begin{array}{l}\text { Intact } \\
\text { shoots }\end{array}$} & $\begin{array}{l}\text { Decapitated } \\
\text { shoots }\end{array}$ & \multicolumn{2}{|c|}{$\begin{array}{l}\text { Decapitated/ } \\
\text { intact shoots }\end{array}$} \\
\hline 14 July & $0.18^{\mathrm{NS}}$ & $(\mathrm{n}=79)$ & & & \\
\hline 1 Sept. & $0.11^{\mathrm{NS}}$ & $(\mathrm{n}=24)$ & $0.33^{* *}(\mathrm{n}=85)$ & $-0.25^{\mathrm{NS}}$ & $(n=24)$ \\
\hline 289 & $0.38^{*}$ & $(n=45)$ & $0.21^{*} \quad(n=80)$ & $0.24^{\mathrm{NS}}$ & $(\mathrm{n}=44)$ \\
\hline 556 & $0.32 * *$ & $(n=61)$ & $0.38 * *(n=84)$ & $-0.36^{* *}$ & $(\mathrm{n}=49)$ \\
\hline 741 & $0.51^{* *}$ & $(n=94)$ & & & \\
\hline 880 & $0.69^{* *}$ & $(\mathrm{n}=94)$ & $0.66^{* *}(n=88)$ & $0.51^{* *}$ & $(\mathrm{n}=88)$ \\
\hline 1098 & $0.72 * *$ & $(\mathrm{n}=94)$ & & & \\
\hline 1193 & $0.67^{* *}$ & $(\mathrm{n}=94)$ & $0.68^{* *}(\mathrm{n}=85)$ & $0.19^{*}$ & $(\mathrm{n}=85)$ \\
\hline 1348 & $0.56^{* *}$ & $(\mathrm{n}=48)$ & & & \\
\hline 1366 & $0.76^{* *}$ & $(\mathrm{n}=45)$ & & & \\
\hline 1602 & ก $77 * *$ & in-2ni & & & \\
\hline
\end{tabular}

${ }^{2} \mathrm{n}=$ Number of genotypes used in the comparison.

, $*$, **Nonsignificant or significant at $P=0.0 .5$ or 0.01 , respectively.

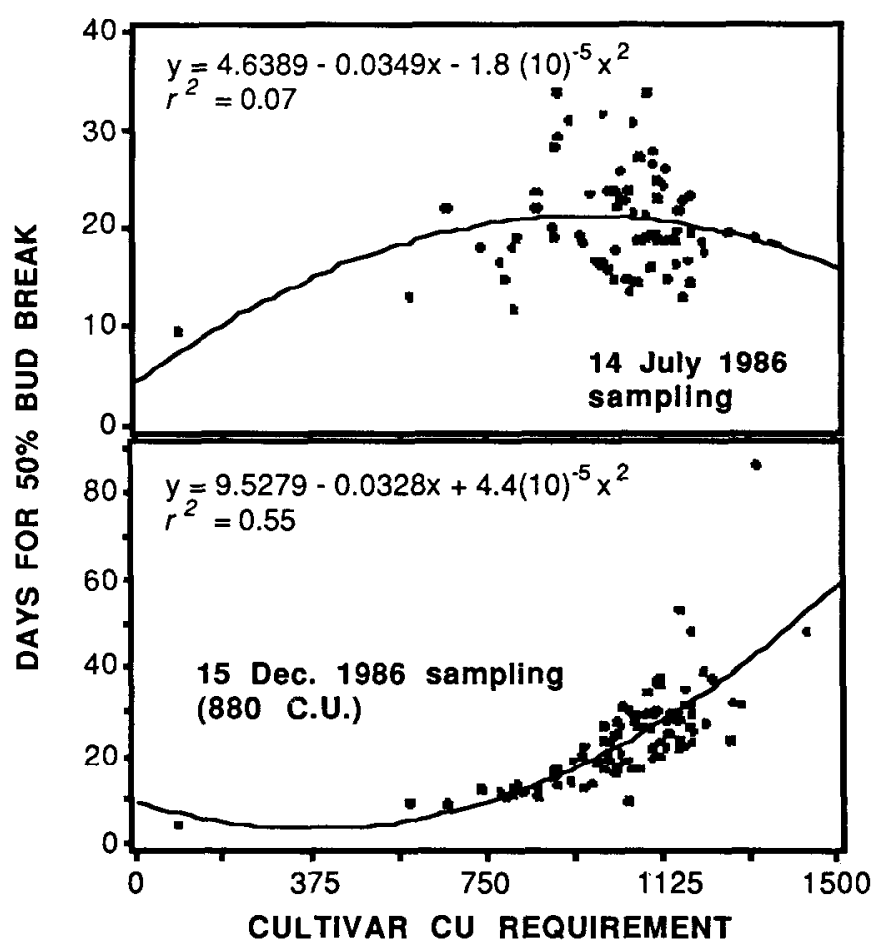

Fig. 5. Relationship between genotype $\mathrm{CU}$ accumulation required to achieve $50 \% \mathrm{BB}$ at the 15 th day of forcing and D50 on two sampling dates of the same genotypes. 
ues were significant at $P=0.001$ and involved 62, 72, and 82 comparisons, respectively. The physiological significance of differences between the estimates is unknown. They reflect genotypic differences in relation to the development of the uppermost bud in response to decapitation. It is possible that a more detailed study on development of budbreak on intact shoots and decapitated ones might increase understanding of dormancy development and termination. In apple, the most obvious symptom of incomplete dormancy release under subtropical conditions is the absence (or very long delay) of lateral vegetative budbreak.

Correlations between $\mathrm{CU}$ accumulation required to D50 = 15 days 2 nd D50 values obtained at several sampling dates for the same genotypes are shown in Table 5. In general terms, terminal bud dormancy intensity during summer is not correlated with the length of bud dormancy observed either in intact shoots (within the cultivars that showed budbreak during the forcing period) or decapitated ones. The relationship improves afterward, stabilizing at $\approx 880 \mathrm{CU}$. This relationship may be helpful for a preliminary screening for CR in a large population. Such screening would be almost impossible by traditional methods, in which frequent sampling throughout the winter is required. For instance, a general idea about the length of bud dormancy (CR) could be derived by sampling at $880 \mathrm{CU}$ accumulation (Fig. 5), but this relationship is almost nonexistent on the 14 July 1984 sampling.

\section{Literature Cited}

Anderson, J. L., E.A. Richardson, and C.D. Kesner. 1986. Validation of chill unit and flower bud phenology models for 'Montmorency' sour cherry. Acts Hort. 184:71-78.

Bennett, J.P. 1949. Temperature and bud rest period. Effect of temperature and exposure on the rest period of deciduous plant leaf buds investigated. Calif. Agr. 3:11, 13, 15-16.

Chapman, P.J. and G.A. Catlin. 1976. Growth stages in fruit trees from dormant to fruit set. N.Y. Food \& Life Sci. Bul. 58.

Couvillon, G.A. and A. Erez. 1985a. Influence of prolonged exposure to chilling temperatures on budbreak and heat requirement for bloom of several fruit species. J. Amer. Soc. Hort. Sci. 110:47-50.

Couvillon, G.A. and A. Erez. 1985b. Effect of level and duration of high temperatures on rest in the peach. J. Amer. Soc. Hort. Sci. 110:579-581.

Erez, A., G.A. Couvillon, and C.H. Hendershott. 1979a. Quantitative chilling enhancement and negation in peach buds by high temperatures in a daily cycle. J. Amer. Soc. Hort. Sci. 104:536-540.

Erez, A., G.A. Couvillon, and C.H. Hendershott. 1979b. The effect of cycle length on chilling negation by high temperatures in dormant peach leaf buds. J. Amer. Soc. Hort. Sci. 104:573-576.

Hatch, A.H. and D.R. Walker. 1969. Rest intensity of dormant peach and apricot leaf buds as influenced by temperature, cold hardiness and respiration. J. Amer. Soc. Hort. Sci. 94:304-307.

Hauagge, R. 1988. Dormancy in Malus seeds and buds: Phenotypic variations, characterization, correlations and inheritance. PhD Diss., Cornell Univ., Ithaca, N.Y.

Hauagge, R. and J.N. Cummins. 1991a. Phenotypic variation of length of bud dormancy in apple cultivars and related Malus species. J. Amer. Soc. Hort. Sci. 116:100--106.

Hauagge, R. and J.N. Cummins. 1991b. Seasonal variation in intensity of bud dormancy in apple cultivars and related Malus species. J. Amer. Soc. Hort. Sci. 116:107-115.

Landsberg, J.J. 1974. Apple fruit bud development and growth: Analysis and an empirical model. Ann. Bet. 38: 1013-1023.

Latimer, J.G. and H.A. Robitaille. 1981. Sources of variability in apple shoot selection and handling for bud rest determinations. J. Amer. Soc. Hort. Sci. 106:794-798.

Overcash, J.P. and J.A. Campbell. 1955. The effects of intermittent warm and cold periods on breaking the rest period of peach leaf buds. Proc. Amer. Soc. Hort. Sci. 66:87-92

Paiva, E. and H.A. Robitaille. 1978a. Breaking bud rest on detached apple shoots. Interaction of gibberellic acid with some rest-breaking chemicals. HortScience 13:57-58.

Paiva, E. and H.A. Robitaille. 1978b. Breaking bud rest on detached apple shoots: Effects of wounding and ethylene. J. Amer. Soc. Hort. Sci. 103:101-104.

Petropoulou, S.P. 1985. Temperature related factors as selection criteria in apple breeding. PhD Diss., Univ. of London.

Richardson, E. A., S.D. Seeley, D.R. Walker, J.L. Anderson, and G.L. Ascroft. 1975. Pheno-climatography of spring peach bud development. HortScience 10:236-237.

Samish, R.M. and S. Lavee. 1962. The chilling requirement of fruit trees. Proc. 16th Intl. Hort. Congr., Brussels. 5:372-388.

Scalabrelli, G. and G.A. Couvillon. 1986. The effect of temperature and bud type on rest completion and the $\mathrm{GDH}^{\circ} \mathrm{C}$ requirement for budbreak in 'Redhaven' peach. J. Amer. Soc. Hort. Sci. 111(4):537540 .

Shaltout, A.D. and C.R. Unrath. 1983. Rest completion prediction model for 'Starkrimson Delicious' apples. J. Amer. Soc. Hort. Sci. 108:957-961.

Singha, S. and L.E. Powell. 1978. Response of apple buds cultured in vitro to abscisic acid. J. Amer. Soc. Hort. Sci. 103:620-622.

Spiegel-Roy, P. and F.H. Alston. 1979. Chilling and post dormant heat requirement as selection criteria for late flowering pears. J. Hort. Sci. 54:115-120.

Tabuenca, M.C. and M.C. Jiménez. 1984. Efectos de distintas temperatures en otoño y en inveirno sobre dos variedades de manzanos. Anales Estacion Expt. Arda Dei. 17:115-149.

Williams, R. R., G.R. Edwards, and B.G. Coombe. 1979. Determination of the pattern of winter dormancy in lateral buds of apples. Ann. Bet. (London) 44:575-581. 